ZOOLOGIA 31 (5): 489-495, October, 2014

http://dx.doi.org/10.1590/S1984-46702014000500009

\title{
A new species of Seira (Collembola: Entomobryidae: Seirini) from Northern Brazil, with the addition of new chaetotaxic characters
}

\author{
Nikolas Gioia Cipola ${ }^{1,3}$, José Wellington de Morais ${ }^{1} \&$ Bruno Cavalcante Bellini $^{2}$
}

\author{
${ }^{1}$ Laboratório de Sistemática e Ecologia de Invertebrados do Solo, CPEN, Instituto Nacional de Pesquisas da Amazônia. \\ Avenida André Araújo 2936, Aleixo, Caixa Postal 478, 69011-970 Manaus, AM, Brazil. \\ 2 Programa de Pós-graduação em Sistemática e Evolução, Departamento de Botânica, Ecologia e Zoologia, Centro de \\ Biociências, Universidade Federal do Rio Grande do Norte. Rodovia BR 101, Lagoa Nova, Campus Universitário, \\ 59072-970 Natal, RN, Brazil. \\ ${ }^{3}$ Corresponding author: Email: nikolasgc@gmail.com
}

\begin{abstract}
Seira caerucinerea sp. nov., a new species of springtail from the Cerrado domain, state of Tocantins, Brazil, is described and illustrated. The new species is mainly characterized by bluish-gray coloration and dorsal chaetotaxy presenting macrochaeta S7 on head, three macrochaetae (a6, m6 and p6) on margin of metathorax and 4+4 macrochaetae (a1, m2, m3 and $\mathrm{m} 4 \mathrm{i}$ ) on abdomen I. Characteristics of maxillary and labial papillae, chaetotaxy of subcoxae, collophore, ventral region of head, ventral and lateral region of abdomen IV and V, which are usually omitted in species descriptions within the genus, are also provided. This is the first species of Seira described from the Cerrado domain, as well as the first record of the genus from the state of Tocantins.
\end{abstract}

KEY WORDS. Biodiversity; Cerrado; Seirinae; taxonomy; Tocantins.

Seira Lubbock, 1870 includes epiedaphic springtails found mostly in litter, from low vegetation to canopy and over uncovered top soils, primarily in tropical landscapes (Christiansen \& Bellinger 2000). It is the fourth most diverse genus of Entomobryidae and the most diverse taxon among the Seirini, comprising around 200 described species worldwide (Bellinger et al. 2014). In the Americas 60 species of the genus have been recorded (CHRISTIANSEN \& BELLINGER 2000), half of them from Brazil, mostly from the Northeastern Region of the country (Godeiro \& Bellini 2014). From the Northern Region of Brazil, only S. nigrans (Arlé, 1959) and S. xinguensis (Arlé, 1959) were recorded until now (Godeiro \& BelLini 2014, Cipola et al. 2014).

The closest genus to Seira is possibly Tyrannoseira Bellini \& Zeppelini, 2011, and both taxa share similar mucronal morphology, overall dorsal chaetotaxy, and habitus. On the other hand, Seira presents a more variable dorsal chaetotaxy, with macrochaetae M1 and M2 present or absent on head; first abdominal segment with or without macrochaetae (absent in Tyrannoseira); and the first pair of legs of males devoid of any clear dimorphic structures (Bellini \& Zeppelini 2011).

Herein we present a new species of Neotropical Seira from the Cerrado Phytogeographic Domain, state of Tocantins, Northern Region of Brazil. The description also presents some data usually omitted in descriptions for the genus.

\section{MATERIAL AND METHODS}

The specimens were collected from leaf litter, preserved in $80 \%$ ethanol, clarified with potassium dichromate $\left(\mathrm{K}_{2} \mathrm{Cr}_{2} \mathrm{O}_{7}\right)$ and hydrochloric acid ( $\mathrm{HCl})$, and mounted on glass slides with Hoyer medium following the procedures described by ArLé \& Mendonça (1982) and Christiansen \& Bellinger (1998). One specimen was photographed in ethanol gel using a stereomicroscope (M165C) attached to a DFC420 digital camera. Photographs were digitally corrected using Leica Application Suite V3.4.1. The general chaetotaxy system used in the descriptions follows JaCquemart (1974) modified by Christiansen \& Bellinger (2000); labial chaetotaxy follows FJeLlberg (1999); maxillary palp follows MARI MutT (1986); and detailed dorsal chaetotaxy follows Szeptycki (1979) and Soto-Adames (2008). Symbols used to depict the chaetotaxy are: large empty circles refer to macrochaetae; small empty circles to mesochaetae; small black circles to microchaetae; large empty circles with a small black dot inside to micro or macrochaetae; line over circles to chaeta present or absent; large black circles with two cross lines to pseudopores; two cross lines to scales; small curved seta to microsensillum; long multiciliated setae to bothriotricum; and triangle near bothriotricum to fan-shaped microchaetae. The material examined is deposited in the Invertebrate Collection of the Instituto Nacional de Pesquisas da Amazônia (INPA), Manaus.

2014 Sociedade Brasileira de Zoologia | www.sbzoologia.org.br | www.scielo.br/zool All content of the journal, except where identified, is licensed under a Creative Commons attribution-type BY-NC. 


\section{TAXONOMY}

\section{Seira caerucinerea sp. nov. Cipola \& Bellini} Figs 1-33

Diagnosis. Distinguished by bluish-gray coloration (Fig. 1), head dorsal chaetotaxy with macrochaeta A5 present in Jacquemart's region 1; 3+3 macrochaetae (M4, S6 and S7) in Jacquemart's region 3; seven to eight macrochaetae (M1, M2, S0, S1, S2, S3, S4 and S5) in Jacquemart's region 4, S5 as macro or microchaeta; $1+1$ (Pa5) in Jacquemart's region 5, mesothorax with $30+30$ to $34+34$ macrochaetae $(a 3 a+, a 3 e+, a 4+, a 4 i$, a5i, a5i2, a5p, a5, m1ia, m1i, m2i2, m2i, m1, m2, m4i, m4p, m4, p1, p1p, p1i, p1i2, p1ip, p1i2p, p2, p2a, p2p, p2e, p2ep, p2ep2, p3 and p3p), a3a+, a3e+ and $\mathrm{m} 2$ present or absent and a $4 \mathrm{i}$ as macro or microchaeta; metathorax with $12+12$ to $13+13$ macrochaetae (m1i, a2, p1i, p1, p2, p2a, p2ia, p3, a4, a5, p6, a6 and m6), p2ia as macro or microchaeta; abdomen I with $4+4$ macrochaetae (a1, m2, m3, and $\mathrm{m} 4 \mathrm{i}$ ); abdomen II with $4+4$ to 5+5 macrochaetae (a2, m3, m3ei, m3e, and m5), m3ei as macro or microchaeta; abdomen III with 6+6 macrochaetae (m3, am6, pm6, p6, a7, p7i and p7); abdomen IV with $25+25$ to $29+29$ macrochaetae (A3a, A3, A4, A5, Ae7, B3, B4, B5, B6, C1, C4, E2, E2p, E3, E4, E4p, E4p2, Ee10, F1, F1p, F2, F2p, F3, F3p, Fe2, $\mathrm{Fe} 3, \mathrm{Fe} 4, \mathrm{Fe} 5$, and Fe6), Ee10, F2p and F3p present or absent and E4p2 as macro or microchaeta; abdomen V with 10+10 macrochaetae (a5, m2, m3, m5, m5e, p1, p3, p4, p5 and one extranumerary) (Figs 21, 23-29, 32).

Description. Total length of the holotype $2.39 \mathrm{~mm}$. Habitus typically entomobryid (Fig. 1). Specimen with bluish-gray color covering the entire body and segments; eye patches area black (Fig. 1). Striated, apically rounded brownish scales covering antennae I and II, basal half of antennae III, head, thorax, abdomen, all segments of legs (except over empodia), collophore, both faces of manubrium and anterior face of dens. Fourth antennal segment not annulated, with a bilobed apical bulb, and smooth and ciliated setae (Fig. 2). Eye patches oval, with largest ocelli A and B and smallest ocellus $\mathrm{H}$, with six interocular setae (Fig. 3). Four prelabral ciliated setae and 14 labral smooth setae $(5 / 5 / 4)$, four anterior (a1 and a2), five median (m0, m1 and $\mathrm{m} 2$ ) and five posterior (p0, p1 and $\mathrm{p} 2$ ) (Fig. 4). Labial region with seta $r$ reduced, M1, M2, E, L1 and L2 ciliated, A1, A2, A3, A4 and A5 smooth (Fig. 5). Labium with five smooth proximal setae. Labial palp with five papillae (A-E), A and C simple, B with three smooth setae (b1, b3 and b4), D with four smooth setae (d1, d2, d3 and d4), and E with lateral process (l.p.) smaller than the papilla and four smooth setae (e1, e2, e3 and e6) (Fig. 6). Maxillary palp with one smooth apical seta (a.s.) and one basal seta (b.s.) the same length (Fig. 7). Left mandible with four incisive teeth, right mandible with five; both mandibles with five molar teeth (Fig. 8). Maxillae with three teeth and one basal spine (Fig. 9). Head ventral chaetotaxy as in Fig. 10. First subcoxa with a row of five to six ciliated macrochaetae and two anterior pseudopori; second

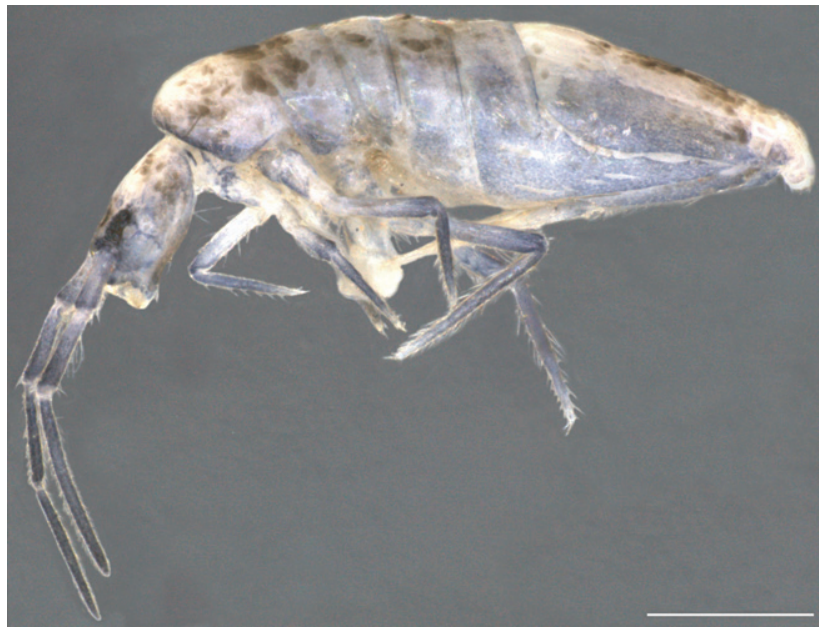

Figure 1. Seira caerucinerea sp. nov.: habitus of a specimen in ethanol. Scale bar: $0.5 \mathrm{~mm}$.

subcoxa with an anterior row (a) of eight macrochaetae, posterior row (p) of five macrochaetae and four pseudopori; third subcoxa with a row of 12 anterior macrochaetae plus two posterior macrochaetae and two anterior pseudopori (Figs 11-13). Trochanteral organ V-shaped with approximately 30 spine-like setae (Fig. 14). Pro-, meso- (Fig. 15, same morphology) and metaungues (Figs 16,17) with four inner teeth, one pair at the base and two unpaired teeth at the apex. Unguiculi trilamelate, acuminate, with two smooth edges and one serrate. Tenent hairs capitate with slightly serrated edges. Tibiotarsus III with a smooth distal seta with enlarged base, near the empodium (Fig. 16). Collophore anterior side with six long ciliated setae; lateral side with seven smooth setae, and twelve ciliated setae; and posterior side with four ciliated setae (Fig. 18). Subapical ventral setae of manubrium with $8+8$ subapical setae, $7+7$ of them on transversal line, one posterior; complete ventral chaetotaxy of manubrium as in Fig. 19. Dens with two rows distally of ciliated setae and mucro typically falcate (Fig. 20). General distribution pattern of dorsal macrochaetae (head and trunk) is shown in Fig. 21.

Dorsal head chaetotaxy (Fig. 23). Antennal series 'An' with $11+11$ to $12+12$ setae, An1a, An1, An2, An2p, An2p2, An3a2, An3a, An3 as macrochaetae and An2a, An3i, An3i2 (present or absent) and An3p as microchaetae; anterior series ' $\mathrm{A}$ ' with A0, A2, A3 and A5 as macrochaetae and A1 and A4 as microchaetae; medio-ocellar series ' $\mathrm{M}$ ' with $5+5$ setae, M1, M2 and M4 as macrochaetae, M3 and M4i as microchaetae and one extranumerary microchaeta near $\mathrm{M} 4$; sutural series ' $\mathrm{S}$ ' with S0, S1, S2, S3, S4, S6 and S7 as macrochaetae and S5 as macro or microchaeta; interocular series with $6+6$ setae, $p$ as macrochaeta and r, t, q, s and one extranumerary (?) as microchaetae; post-sutural series 'Ps' with $3+3$ microchaetae (Ps2, Ps3 and Ps5) and Ps4 absent (typical of Seira); postoccipital anterior series ' $\mathrm{Pa}$ ' with $6+6$ setae, $\mathrm{Pa} 5$ as macrochaeta, $\mathrm{Pa} 1$, 


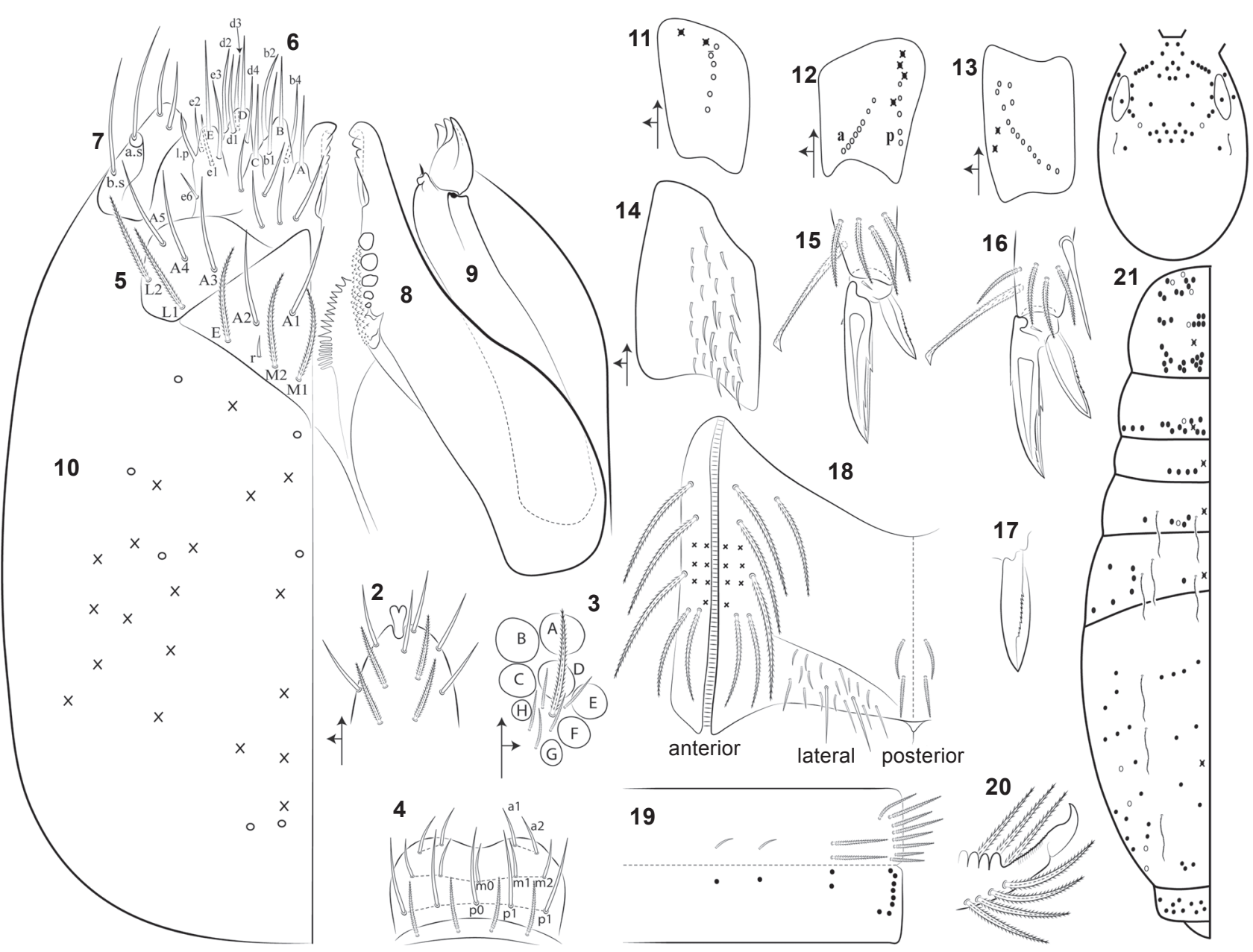

Figures 2-21. Seira caerucinerea sp. nov.: (2) apical bulb of the fourth antennal segment; (3) eye patch (right); (4) prelabral and labral chaetotaxy; (5) labial region (left); (6) labial palp; (7) maxillary palp; (8) mandible; (9) maxilla (right); (10) head ventral chaetotaxy; (11) subcoxa I; (12) subcoxa II; (13) subcoxa III; (14) trochanteral organ; (15) foot I complex; (16) foot III complex; (17) metaunguiculus (posterior view); (18) collophore chaetotaxy; (19) manubrium chaetotaxy (ventral view); (20) distal dens and mucro; (21) general distribution of dorsal macrochaetae on head and trunk.

$\mathrm{Pa} 2, \mathrm{~Pa} 3$ and $\mathrm{Pa} 4$ as microchaetae and $\mathrm{Pa} 6$ as bothriotricum; postoccipital median series 'Pm' with 2+2 microchaetae (Pm1 and Pm3), Pm2 absent (typical of Seira); postoccipital posterior 'Pp' series with 6+6 microchaetae (Pp1, Pp2, Pp3, Pp4, Pp5 and Pp6); postoccipital external series ' $\mathrm{Pe}^{\prime}$ with microchaeta Pe3 present.

Dorsal mesothorax chaetotaxy (Fig. 24). Anterior series ' $a$ ' with $11+11$ to $13+13$ setae, a3e+ complex (one chaeta can be absent), a3a+ complex (one seta can be absent), a4+, a5i2, a5i, a5p and a5 as macrochaetae, a $4 \mathrm{i}$ as macro or microchaeta, a2p and a5ip as microchaetae; medial series ' $\mathrm{m}$ ' with $15+15$ to $16+16$ setae; $\mathrm{m} 1 \mathrm{ia}, \mathrm{m} 1 \mathrm{i}, \mathrm{m} 2 \mathrm{i} 2, \mathrm{~m} 2 \mathrm{i}, \mathrm{m} 1, \mathrm{~m} 2$ (present or absent), $\mathrm{m} 4 \mathrm{i}, \mathrm{m} 4 \mathrm{p}$ and $\mathrm{m} 4$ as macrochaetae, $\mathrm{m} 1 \mathrm{i} 3, \mathrm{~m} 1 \mathrm{i} 2, \mathrm{~m} 4 \mathrm{ip}$, $\mathrm{m} 5 \mathrm{a}, \mathrm{m} 5$ and $\mathrm{m} 5 \mathrm{p}$ as microchaetae and one extranumerary microchaeta of uncertain homology (?) between m1ia and m1i2; posterior series 'p' with 20+20 setae; "PmA" group (see Soto-ADAmEs 2008) with six macrochaetae (p1, p1p, p1i2p, p1i, p1ip and p1i2) and one extranumerary microchaeta (?); "PmB" group with three macrochaetae (p2, p2a and p2p) and one extranumerary microchaeta (?); "PmC" group with five macrochaetae (p3, p3p, p2e, p2ep and p2ep2) and p2ea and p4 as microchaetae. Microchaetae p5 and p6 present; p6e, p6ep, p6ep2 and p6ep3 missing.

Dorsal metathorax chaetotaxy (Fig. 25). Series 'a' with 6+6 setae, a2, a4, a5 and a 6 as macrochaetae, a1 and a7 as microchaetae; series ' $\mathrm{m}$ ' with $10+10$ setae, $\mathrm{m} 1 \mathrm{i}$ and $\mathrm{m} 6$ as macrochaetae, $\mathrm{m} 6 \mathrm{p}$ as mesochaeta, $\mathrm{m} 1, \mathrm{~m} 4, \mathrm{~m} 5, \mathrm{~m} 6 \mathrm{p} 2, \mathrm{~m} 7$ and one extranumerary (?) as microchaetae and m7e as 
microsensillum; series ' $\mathrm{p}$ ' with 10+10 setae, p1i, p1, p2, p2a, p3 and p6 as macrochaetae, p2ia as macro or microchaeta and p2ea, p4 and p5 as microchaetae.

Dorsal abdominal segment I chaetotaxy (Fig. 26). Series ' $a$ ' with $8+8$ setae, a1 as macrochaeta, a1a, a1e, a2, a3, a5 and a6 as microchaetae and a6e as microsensillum; series ' $\mathrm{m}$ ' with $6+6$ setae, $\mathrm{m} 2, \mathrm{~m} 3$ and $\mathrm{m} 4 \mathrm{i}$ as macrochaetae and $\mathrm{m} 4, \mathrm{~m} 5$ and $\mathrm{m} 6$ as microchaetae; series ' $\mathrm{p}$ ' with 2+2 microchaetae (p5 and p6).

Dorsal abdominal segment II chaetotaxy (Fig. 27). Series 'a' with 7+7 setae, a2 as macrochaeta, a3, as, a6 and a7 as microchaetae, a2p as fan-shaped microchaeta and a5 as bothriotricum with six surrounding fan-shaped microchaetae; series ' $\mathrm{m}$ ' with $8+8$ setae, $\mathrm{m} 3, \mathrm{~m} 3 \mathrm{e}$ and $\mathrm{m} 5$ as macrochaetae, $\mathrm{m} 3$ ei as macro or microchaeta, $\mathrm{m} 3 \mathrm{ea}, \mathrm{m} 6$ and $\mathrm{m} 7$ as microchaetae and $\mathrm{m} 2$ as bothriotricum with four surrounding fan-shaped microchaetae; series 'p' with $3+3$ setae, p6 as mesochaeta and p5 and p7 as microchaeta. Microchaeta se present near p6 and seta el missing.

Dorsal abdominal segment III chaetotaxy (Fig. 28). Series ' $a$ ' with $8+8$ setae, am 6 and a7 as macrochaetae, as and a3 as microchaetae, a1, a 2 and a 6 as fan-shaped microchaetae and a5 as bothriotricum; series ' $\mathrm{m}$ ' with $6+6$ setae, $\mathrm{m} 3$ as macrochaeta, $\mathrm{m} 7$ as microchaeta, $\mathrm{m} 4$ and $\mathrm{m} 3$ ea fan-shaped microchaetae and $\mathrm{m} 2$ and $\mathrm{m} 5$ as bothriotrica; series ' $\mathrm{p}$ ' with 7+7 setae, pm6, p6, p7i and p7 as macrochaetae, p7e as mesochaeta, p5 as microchaeta and p3 as fan-shaped microchaetae. Microchaeta se present between pm6 and p6 and accessory microchaeta d2 present near p5. Eight fan-shaped microchaetae (c3, emp, em and five unnamed) present between bothriotrica a5 and $\mathrm{m} 5$ as two unnamed fan-shaped microchaetae surrounding bothriotricum $\mathrm{m} 2$. Seta el present as mesochaeta.

Dorsal abdominal segment IV chaetotaxy (Fig. 29). Series ' $\mathrm{A}$ ' with 7+7 setae, A3a, A3, A4 and A5 as macrochaetae and A1, $\mathrm{A} 2$ and $\mathrm{A} 6$ as microchaetae; Ae7 present as macrochaeta; series 'B' with 6+6 setae, B3, B4, B5 and B6 as macrochaetae and B1 and $\mathrm{B} 2$ as microchaetae; series ' $\mathrm{C}$ ' with $4+4$ setae, C1 and C4 as macrochaeta, C2 and C3 as microchaetae; C1p absent; series ' $\mathrm{T}$ ' with $8+8$ setae, T7 as mesochaeta, T1, T3, T5 and T6 as microchaetae, T2 and T4 as bothriotrica with T1p, s and $\mathrm{m}$ as fan-shaped microchaetae near T2 and Pe, T4a and Pi near T4; series ' $\mathrm{D}$ ' with $6+6$ setae, D3p as mesochaeta, D1p, D2a and D2 as microchaetae, D1 as fan-shaped microchaeta and D3 as bothriotricum; series 'E' with 7+7 setae, E2, E2p, E3, E4 and E4p as macrochaetae, E4p2 as macro or microchaeta and E1 as microchaeta; Ee10 macrochaeta present or absent; series ' $\mathrm{F}$ ' with 4+4 to 6+6 macrochaetae (F1, F1p, F2, F2p, F3 and F3p), F2p and F3p present or absent; series ' $\mathrm{Fe}^{\prime}$ with 5+5 macrochetae (Fe2, Fe3, Fe4, Fe5 and Fe6). Eight extranumerary microchaetae present between the series ' $\mathrm{A}$ ' to ' $\mathrm{E}$ ' and microchaeta ps near T7. Posterior margin of abdominal segment IV with 7+7 unnamed mesochaetae.

Lateral abdominal segment IV chaetotaxy (Fig. 30). Series ' $\mathrm{G}$ ' with $\mathrm{G} 1$ as mesochaeta and series ' $\mathrm{H}$ ' with $4+4$ mesochaetae (H1, H2, H3 and H4).
Ventral abdominal segment IV chaetotaxy (Fig. 31). Series 'I' with $4+4$ to $5+5$ mesochaetae (I1, I2, I3, I4 and I5), I5 present or absent; series ' $\mathrm{J}$ ' with $3+3$ mesochaetae (J1, J2 and J3); series ' $\mathrm{K}$ ' with $5+5$ mesochaetae (K1, K3, K3p, K4 and K5); series 'Ke' with 12+12 to 14+14 mesochaetae (Ke1, Ke2, Ke2p, Ke3, Ke4, Ke5, Ke6, Ke7, Ke8 and five unnamed), two present or absent.

Dorsal abdominal segment $\mathrm{V}$ chaetotaxy (Fig. 32). Series 'a' with 5+5 setae, a5 as macrochaeta, a1, a3, as, a3ae and one extranumerary (?) as microchaetae and a6 absent (atypical); series ' $\mathrm{m}$ ' with $6+6$ setae, $\mathrm{m} 2, \mathrm{~m} 3, \mathrm{~m} 5$ and $\mathrm{m} 5$ e as macrochaetae and $\mathrm{m} 5 \mathrm{a}$ as mesochaeta; posteroanterior series 'pa' with 4+4 setae, p5a as mesochaeta and p3a, p4a and p6ai as microchaetae and p6ae absent (atypical); series ' $\mathrm{p}$ ' with $8+8$ setae, p0 absent, p1, p3, p4, p5 and one extranumerary (?) as macrochaetae, ap6 and ap6e as mesochaetae and pp6 as microchaeta; posterior-posterior series 'pp' with 3+3 microchaetae (p1p, p3pi and p3pe). One unnamed microchaeta typically present between series ' $\mathrm{m}$ ' and ' $\mathrm{p}$ '.

Lateral abdominal segment $\mathrm{V}$ chaetotaxy with $4+4$ mesochaetae (Fig. 33).

Examined material. Holotype male on slide COLLE 037/ INPA, Brasil, Tocantins, Palmas, Taquaruçu district, "Fazenda Ecológica de Taquaruçu" $\left(10^{\circ} 15^{\prime} \mathrm{S}, 48^{\circ} 08^{\prime} \mathrm{W}\right), 13-20 . v \cdot 2013$, pitfall-trap, A. S. Lopes coll. Paratypes: 1 male, 18 females and 2 immature on slides COLLE 037A-T/INPA; and 6 specimens in ethanol $92^{\circ} \mathrm{GL}$, same data as holotype.

Etymology. The name "caerucinerea" refers to the blue to gray color of the new species (from Latin: caeruleo and cinereo).

Distribution and habitat. The species was so far only found in its type locality at the state of Tocantins, Brazil. Good's biogeographic zone 27 of the Neotropical region, Highlands of Eastern Brazil: North Brazilian (GooD 1974). The climate of the area, according to the Köppen-Geiger system, is tropical (Aw) with predominance of the dry season (Коттек et al. 2006). This is the first species of Seira described from the Cerrado domain, as well as the first record of the genus from the state of Tocantins.

Remarks. The dorsal pattern of chaetotaxy in Seira caerucinerea sp. nov. resembles $S$. insalahi Jacquemart, 1974 from Algeria, north Africa, and S. paraibensis Bellini \& Zeppelini, 2009 from northeastern Brazil. The new species differs from the others by its dorsal head chaetotaxy, which presents seta S4 as macro or microchaeta, and by the presence of interocular (p) macrochaeta (absent in S. insalahi and S. paraibensis) (Figs 21, 23). Seira caerucinerea sp. nov. also presents a very peculiar dorsal chaetotaxy on mesothorax, with six macrochaetae in "PmA" group (p1, p1i, p1p, p1ip, p1i2 and p1i2p), whereas there are five in $S$. paraibensis and seven in $S$. insalahi; metathorax with three macrochaetae (a6, m6 and p6) in the lateral margin of tergite; abdominal segment I with four macrochaetae (a1, m2, m3 and $\mathrm{m} 4 \mathrm{i}$ ); and abdominal segment IV with 25 to 29 macrochaetae (E4p2, Ee10, F2p and F3p present 


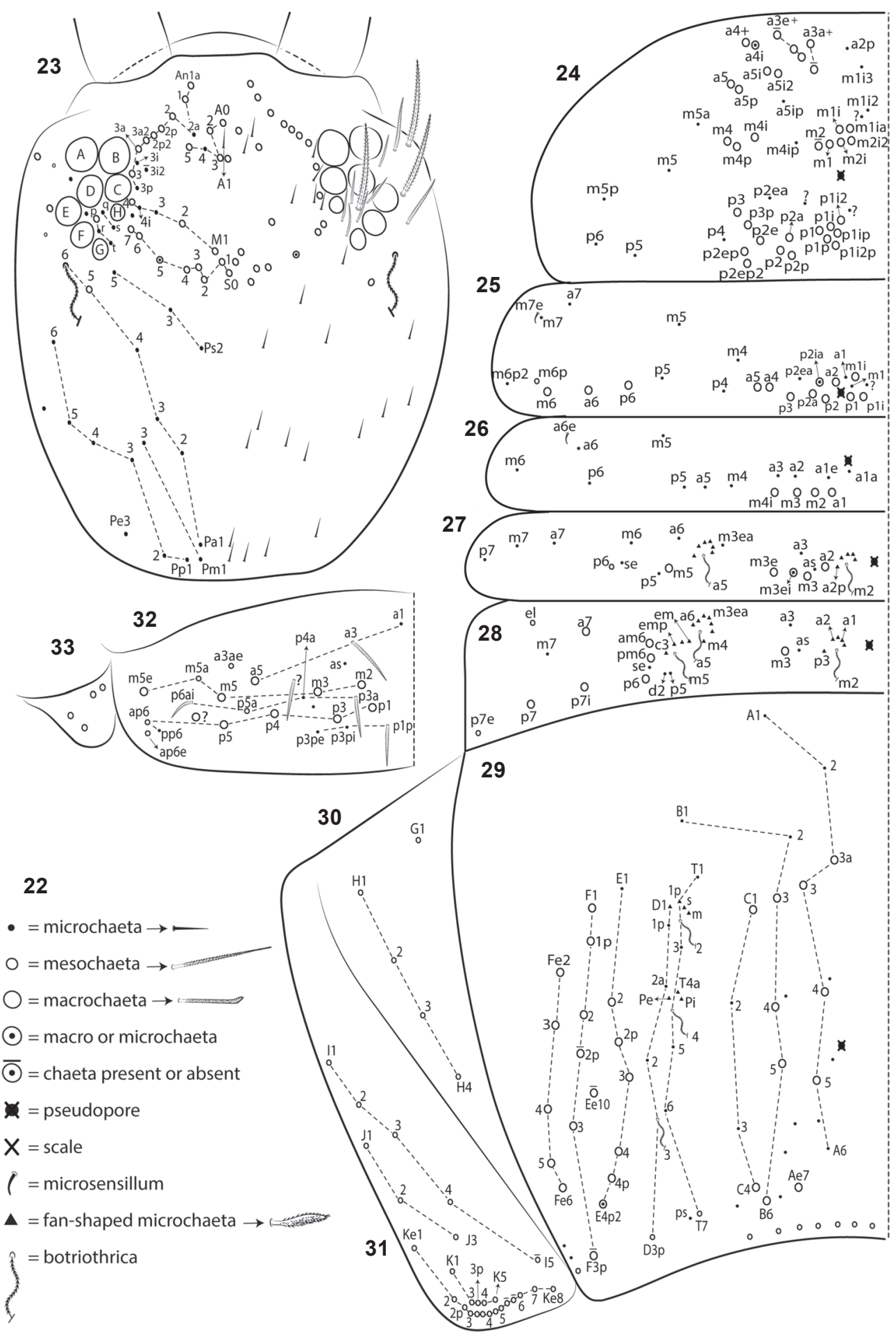

Figures 22-33. Seira caerucinerea sp. nov.: (22) symbols used in detailed chaetotaxy schemes; (23) dorsal head chaetotaxy; (24) dorsal mesothorax chaetotaxy; (25) dorsal metathorax chaetotaxy; (26) dorsal abdomen I chaetotaxy; (27) dorsal abdomen II chaetotaxy; (28) dorsal abdomen III chaetotaxy; (29) dorsal abdomen IV chaetotaxy; (30) dorsal abdomen V chaetotaxy; (31) lateral abdomen IV chaetotaxy; (32) ventral abdomen IV chaetotaxy; (33) lateral abdomen V chaetotaxy. 
or absent); all these features (Figs 21, 23-29) distinguish the new species from $S$. paraibensis and $S$. insalahi.

In addition to these characteristics, $S$. caerucinerea sp. nov. can be distinguished from $S$. paraibensis by the shape of unguiculi, which is acuminate with serrate edges in the new species and truncate with smooth edges in $S$. paraibensis (see Bellini \& Zeppelini 2009). Also, S. caerucinerea sp. nov. is the only one that presents a smooth seta in metaungues (Figs 1517). Finally, both species present very distinct color patterns.

\section{DISCUSSION}

The chaetotaxic characteristics added in the description of $S$. caerucinerea sp. nov. are usually omitted in descriptions of Seira species and most other Entomobryoidea (ventral head chaetotaxy, prelabral and labral setae, labial papilla setae, maxillary palp setae, chaetotaxy of subcoxae and collophore, lateral and ventral region of the abdominal segments IV and V). These added characteristics provide new directions and features to compare species in the genus and in higher taxa. It is possible that some of these characters can also provide phylogenetic information, since they are stable within the genus, or even within Seirini. For instance, the prelabral and labral setae formulae described for $S$. caerucinerea sp. nov. (Fig. 4) can also be observed in S. urbana Nguyen, 2001, S. desapercebida Soto-Adames, 2002, S. dinizi da Gama, 1888 and S. taeniata (Handschin, 1925) (see Yosi 1990: 536). Other examples are the five proximal smooth setae and five (A-E) labial papillae (Fig. 6), which are invariant in Seira and among the genera of Entomobryidae (CHRISTIANSEN \& Bellinger 1998, Fjellberg 1999, Xu et al. 2013). These features were also similarly described for $S$. socotrae Barra, 2004 and $S$. vanharteni Barra, 2004 (see BARRA 2004: 404, 406).

Furthermore, other features vary among Seira species or at least among the Entomobryidae genera. The chaetotaxy of collophore can be quite variable in species of Seira and other Entomobryidae (YosII 1990, BARRA 2004, 2010). However, species like S. iricolor Yosii \& Ashraf, 1964, S. oligoseta Lee \& Park, 1989 , and $S$. vanharteni have a somewhat similar pattern to $S$. caerucinerea sp. nov. (Fig. 18). The chaetotaxy of the maxillary palp and subcoxae were described for other Entomobryidae genera, such as Acrocyrtus, Lepidocyrtus and Pseudosinella (MARI MutT 1986, Xu et al. 2013) and are more stable, especially the first characteristic (Fig. 7). Nevertheless, small differences can be detected among the few descriptions that provide such information. The stability of this particular morphological characteristic can only be proven by means of a revision of the already described species. The ventral chaetotaxy of the head has rarely been described. Only $S$. desapercebida (see Soto-ADAmES 2002: 96) and S. caerucinerea sp. nov. descriptions provide this information among Neotropical Seira (Fig. 10). This character varies greatly among Entomobryoidea species, but the comparison between the new species and $S$. desapercebida shows some similar (and possibly stable) groups of setae.
Finally, the lateral and ventral chaetotaxy of the abdominal segments IV and V of S. caerucinerea sp. nov. are described here for the first time for Entomobryoidea (Figs 30, 31, 33). Even if these features are difficult to visualize, they can provide important elements and bring new insights into species comparisons of Seira and other Entomobryoidea. New descriptions and revisions will possibly support this point of view and the viability of comparing these taxonomic features.

\section{ACKNOWLEDGMENTS}

We thank Ana S. Lopes, Carmen Dionísio (UFT), and Vanessa Ferreira (UFAM) for providing the specimens. The first author is granted by CAPES and CNPq. The last author is granted by $\mathrm{CNPq}$ /Programa de Pesquisa em Biodiversidade Invertebrados (PPBio)/Pró-reitoria de Pesquisa - Universidade Federal do Rio Grande do Norte (PROPESQ - UFRN).

\section{LITERATURE CITED}

Arlé, R. \& C. Mendonça. 1982. Estudo preliminar das espécies de Dicranocentrus Schött, 1893, ocorrentes no Parque Nacional da Tijuca, Rio de Janeiro (Collembola). Revista Brasileira de Biologia 42 (1): 41-49.

BARRA, J.A. 2004. Springtails of the genus Seira Lubbock, 1869 (Collembola: Entomobryidae) from Socotra Island. Fauna of Arabia 20: 399-408.

BARra, J.A. 2010. Une nouvelle espèce de Seira Lubbock, 1869 (Collembola, Entomobryidae) de Tunisie présentant des caractères sexuels secondaires. Zoosystema 32 (4): 585-593.

Bellinger, P.F.; K.A. Christiansen \& F. Janssens. 1996-2014. Checklist of the Collembola of the World. Available online at: http://www.collembola.org [Accessed: 10/VI/2014]

Bellini, B.C. \& D. Zeppelini. 2009. A new species of Seira Lubbock (Collembola, Entomobryidae), with a key to the species of Paraíba, Brazil. Revista Brasileira de Entomologia 53: 266271.

Bellini, B.C. \& D. Zeppelini. 2011. New genus and species of Seirini (Collembola, Entomobryidae) from Caatinga Biome, Northeastern Brazil. Zoosystema 33: 545-555. doi: 10.5252/ z2011n4a6

Christiansen, K. \& P. Bellinger. 1998. The Collembola of North America North of Rio Grande. A taxonomic analysis. Grinnell, Grinnell College, 1520p.

Christiansen, K. \& P. Bellinger. 2000. A survey of the genus Seira (Collembola: Entomobryidae) in the Americas. Caribbean Journal of Science 36: 39-75.

Cipola, N.G.; J.W. Morais \& B.C. Bellini. 2014. Two new species of Seira Lubbock (Collembola, Entomobryidae, Seirini) from South Brazil. Zootaxa 3793: 147-164. doi: 10.11646/ zootaxa.3793.1.7

Fjellberg, A. 1999. The labial palp in Collembola. Zoologischer Anzeiger 237: 309-330. 
Godeiro, N.N. \& B.C. Bellini. 2014. Three new species of Seira Lubbock (Collembola, Entomobryidae) from Caatinga Domain, northeastern Brazil. Zootaxa 3764: 131-151. doi: 10.11646/zootaxa.3764.2.2

Good, R. 1974. The geography of flowering plants. London, Longman Group, $4^{\text {th }}$ ed., $574 \mathrm{p}$.

Jacquemart, S. 1974. Resultats de la Mission Anthropologique Belge au Niger. Collemboles nouveaux du Sahara. Bulletin de l'Institut Royal des Sciences Naturelles de Belgique 50 (6): 1-46.

Kottek, M.; J. Grieser; C. Beck; B. Rudolf \& F. Rubel. 2006. World map of the Köppen-Geiger climate classification updated. Meteorologische Zeitschrift 15: 259-263. doi: 10.1127/ 0941-2948/2006/0130

Mari Mutt, J.A. 1986. Puerto Rican species of Lepidocyrtus and Pseudosinella (Collembola: Entomobryidae). Caribbean Journal of Science 22 (1-2): 1-48.
Soto-AdAmes, F.N. 2002. Four new species and new records of springtails (Hexapoda: Collembola) from the US Virgin Islands and Puerto Rico, with notes on the chaetotaxy of Metasinella and Seira. Caribbean Journal of Science 38: 77-105.

Soto-ADAmEs, F.N. 2008. Postembryonic development of the dorsal chaetotaxy in Seira dowlingi (Collembola, Entomobryidae); with an analysis of the diagnostic and phylogenetic significance of primary chaetotaxy in Seira. Zootaxa 1683: 1-31.

SZEPTYCKI, A. 1979. Chaetotaxy of the Entomobryidae and its phylogenetical significance. Morpho-systematic studies on Collembola, IV. Krakow, Polska Akademia Nauk, 216p. Xu, G.L.; Z.X. PAN \& F. Zhang. 2013. First record of Acrocyrtus Yosii, 1959 (Collembola, Entomobryidae) from Chinese mainland. ZooKeys 260: 1-16. doi: 10.3897/zookeys.260.3770

Yosil, R. 1990.Miscellaneous notes on the Collembola of Macronesia. Contributions from the Biological Laboratory Kyoto University 27 (4): 535-540.

Submitted: 19.VI.2014; Accepted: 16.IX.2014.

Editorial responsibility: Gabriel L.F. Mejdalani 